\title{
EFFECT OF PLATFORM SWITCHED IMPLANTS ON SUPPORTING STRUCTURES OF MANDIBULAR OVERDENTURES
}

\author{
Neveen Samy Abd El Rahim* and Asmaa Abd El Fattah Ashour **
}

\begin{abstract}
Twenty completely edentulous patients with age ranged between 50 and 60 years were selected for this study. Complete dentures were constructed for all patients. The patients were divided into two groups; ten patients each. The first group was received two platform switched implants (3.6 $\times 11.5 \mathrm{~mm}$ ) in the canine regions of the mandible. The second group was received two platform matched implants $(3.6 \times 11.5 \mathrm{~mm})$ in the canine regions of the mandible according to two stage surgical protocol. Radiographic and clinical evaluations were performed throughout the twelve months follow up. The result of the study revealed that there were no statistically significant differences in marginal bone loss between mandibular overdentures retained by two platform switched implants and that retained by two platform matched implants. Also, there were no statistically significant differences in pocket depth or implant mobility between two studied groups. This study concluded that platform switching didn't influence marginal bone loss around implants or soft tissue supporting mandibular overdenture dentures.
\end{abstract}

\section{INTRODUCTION}

Rehabilitation of edentulous mandibles by means of implant-retained overdentures is well established and documented. A mandibular overdenture supported by two implants is an effective treatment alternative especially for the maladaptive denture wearer. It affords greater retention, support and stability. ${ }^{(1,2)}$

Implant marginal bone loss seems to be unavoidable due to bone remodeling and resorption of the crestal bone after the insertion of the implant and prosthetic connection. Peri-implant marginal bone loss (MBL) at the shoulder abutment connection has been associated with biological complications that may trigger inflammatory events and further progressing to peri-implant diseases. ${ }^{(3,}$ 4) Peri-implant tissue adaptations may result from the presence of biological width following implant rehabilitation, bacterial colonization at the implant shoulder-abutment interface and stress concentration at the implant shoulder during function. Minimal or no marginal bone loss after implant-abutment connection is considered to be an indicator of longterm success of implant restoration. ${ }^{(5,6)}$

\footnotetext{
*Associate Professor of Removable Prosthodontics, Faculty of Dental Medicine for Girls, Al Azhar University.

**Lecturer of Removable Prosthodontics, Faculty of Dental Medicine for Girls, Al Azhar University.
} 
Implant position and design, as well as dimensions of the abutment superstructure, influence the way in which occlusal forces are transmitted to the implant and the surrounding bone. Although the abutments used with conventional implant types are generally flush with the implant shoulder in the contact zone, formation of microcracks between the implant fixture and the abutment has been observed. Studies have shown that bacterial contamination of the microcracks between the implant and the abutment adversely affects the stability of the peri-implant tissues. $^{(7-9)}$

In an attempt to improve long-term bone maintenance around implants, implant-to abutment connection referred to as "platform switching" has been proposed. It refers to the use of an abutment of smaller diameter connected to implant neck of larger diameter. The underlying principle for platform is to locate the micro-gap of the implant-abutment interface far away from the vertical bone-to-implant contact area. ${ }^{(10,11)}$

It was assumed that through the inward positioning of the implant/abutment junction; the distance of the junction in relation to the adjacent crestal bone and the surface area to which the soft tissue can attach and establish a biological width was increased and therefore bone resorption at the implant-abutment junction associated with the inflammatory cell infiltrate was reduced. ${ }^{(12,13)}$

During the osseointegration process, primary mechanical stability is gradually replaced by biological stability. When the healing phase is completed, primary mechanical stability is totally replaced by biological stability. Thanks to resonance frequency analysis it is possible to control implant stability non-invasively throughout the entire healing period. ${ }^{(14,15)}$

The aim of this study was to evaluate the effect of two platform switched implants on supporting structures of mandibular overdenture by evaluating the marginal bone loss and soft tissue changes as regarding probing depth and implant mobility.

\section{MATERIALS AND METHODS}

Twenty completely edentulous patients with age ranged between 50 and 60 years were selected for this study. Patients were free from any debilitating systemic diseases that may disturb normal healing process, oral pathologies, TMJ disorders or bone diseases. All patients had Angle's class I jaw relationship and enough inter-arch space. Their ridges had adequate contour which covered with firm and healthy mucosa. A period of at least six months was elapsed from the last extraction. All patients accepted the treatment and provided written accepted consent. All patients were evaluated through preoperative panoramic radiograph to examine the condition of the bone height and a preliminary idea about the quality and quantity of the bone was concluded. Also cone beam computed tomography (CBCT) was taken with a radiographic template to determine the availability of bone height and bucco-lingual width for implant placement. Bone quality especially at the expected implant sites was determined and the position of mental foramen was also detected. All patients were received complete maxillary and mandibular dentures. Dentures were constructed following the conventional clinical and laboratory techniques. All patients were instructed to use their dentures for three months as minimal adaptation period after delivery. For each patient, a cone beam radiograph with radiographic stent in place was taken to evaluate alveolar bone quality and quantity at the proposed implants positions. Then the patients were divided into 2 groups; ten patients for each. The first group (GI) was received two tapered, self tapping, endosteal; platform switched implants $(3.6 \times 11.5 \mathrm{~mm})$ in the canine regions of the mandible (Dyna Dental Engineering BV, Holland). The second group (GII) was received two tapered, self tapping, endosteal; platform matched implants $(3.6 \times 11.5 \mathrm{~mm})$ in the canine regions of the mandible (Dyna Dental Engineering BV, Holland). The implants in both groups were installed according to the two stage flapless surgical protocol and were kept 
submerged for three months for osseointegration. After three months, the implants were exposed, and implant cover screw were unthreaded and replaced by healing collar. The fitting surface areas opposing the healing collars were relived to accommodate the healing collars. After ten days the healing collars were replaced by abutments of the ball and socket attachments (Dyna Dental Engineering BV, Holland). The denture fitting surface was modified to accommodate the female parts of the attachments; autoplomariezed acrylic resin was added in the relieved areas. The patient was asked to close in centric occlusion until complete polymerization. The mandibular overdenture was now retained by two ball and socket attachments connected to two platform switched dental implants in the first group, while retained by two ball and socket attachment connected to two platform matched dental implant in the second group., figure (fig.(1)).

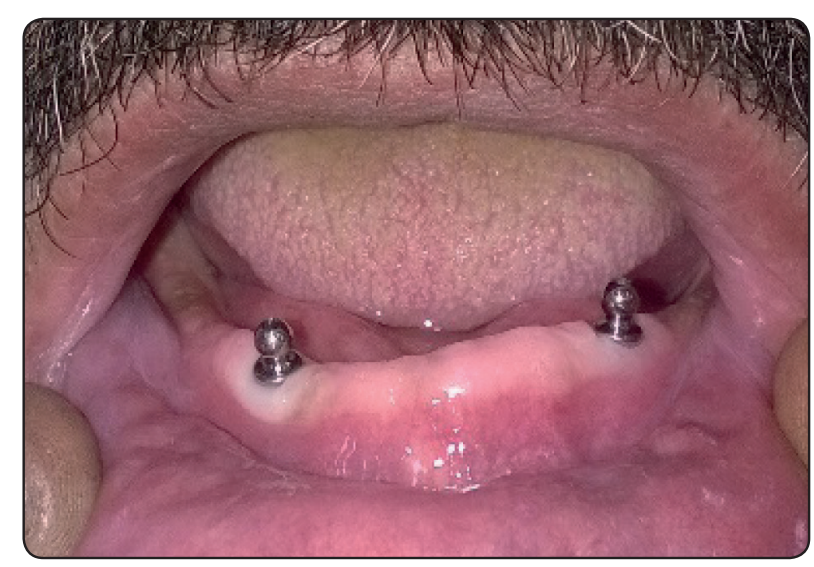

Fig. (1): Two platform switched dental implants in the canine regions of the mandibular ridge.

Radiographic evaluation and clinical measures were made at the time of denture insertion after implants loading for all patients. In both groups the patients used their dentures twelve months. Follow up radiographic measures were made after 12 months for each group while clinical measures were made at loading, 6 months and 12 months after loading, as the following:

\section{1- Radiographic evaluation}

\section{Measurements of marginal bone loss (linear analysis)}

An acrylic resin template was constructed for each patient to standardize the radiographic procedure and allow easy, repeatable and accurate placement of the image plate with the holder to the template during different follow up intervals. Radiographic follow up was performed for assessment of the marginal bone loss mesial and distal to each implant. Standardized digital images for the mandibular ridge were obtained, in this study, using Dürr vistascan system (Dürr Dental Gm bH \& Co. Germany) to calculate measurements of marginal bone loss using image processing software (Dürr DBS-Win, Dürr Dental, Germany). Serial standardized periapical radiographs were made following the long cone paralleling technique using the image plate mounted on $\mathrm{x}$ - ray film holder (Kerr Hawe SA, Switzerland) in conjunction with the previous template. Following the image plate exposure, the image plate was removed from the patient's mouth and was inserted in the film cassette of Dürr vistascan system. The film cassette was placed in the scanner of Dürr vistascan system and scanning was undertaken. The image was displayed on the screen gradually. After the readout was completed, the newly read image was saved on the patient folder automatically. The saved images of eachpatient were interpreted to record marginal bone loss mesial and distal to each implant by one examiner at three different times. The mean of the three readings was calculated. Linear measurements in $\mathrm{mm}$ for the assessment of marginal bone loss were made. The implant shoulder and the alveolar crest of the bone were used as reference points. The distance from the implant shoulder to the apex of the implant was measured, which was then used to divide the known original length of the implant from the finish line to the apex to calculate the 
magnification factor. The magnification factor was then multiplied by the measured distance on mesial and distal sides of implant to derive the actual distance of bone loss. The distance from the alveolar crest to the end of the implant on its mesial and distal sides was calculated. This was carried out at each scheduled follow up visit. The data were collected and statistically analyzed.

\section{2- Clinical evaluation}

\section{A. Probing depth measurement}

Hawe Neos colour-coded (3/5/7/9mm) plastic periodontal probe with flexible tip (Kerr, Lugano, Switzerland) specially designed for measuring pocket depth around implants was used. The probe was positioned parallel to the long axis of the implant and kept in contact with the implant surface. The distance between marginal border of the gingiva and the tip of a plastic periodontal probe was recorded as probing depth (PD). PD measurements are recorded for 4 specific sites on each implant on the following sequence; facial, lingual, mesial and distal. Only one reading per site is recorded. PD measurements were recorded to the nearest full millimeter and recorded on a periodontal chart and become a permanent part of the patient chart. The mean of right and left implant measurements per patient was subjected to statistical analysis.

\section{B. Implant mobility}

Implant Stability Quotient (ISQ) measurement scale and Resonance Frequency Analysis (RFA) was used to evaluate implant stability. The measurement was performed by utilizing the Osstell ISQ (Osstell $\mathrm{AB}$, Gothenburg - Sweden). The ISQ values range from 1-100. The more stable the implant the higher the ISQ value. The following steps were achieved: Ball attachment was unscrewed and a smartpeg specially supplied for the previously used implants (smartpeg number 27) was attached to the abutment using the smartpeg Mount. The connection should be "finger-tight" (approximately4-6 Ncm tightening torque). The hand-held measurement probe was held close to the smartpeg at a contact-free distance ensuring that the tip of the probe was pointing at the top of the smartpeg magnet. The smartpeg was stimulated with the probe magnetic pulses, as soon as the measurement was recorded an audible sound was heard. The ISQ value was shown on the display. Two perpendicular measurements was achieved, the highest and the lowest ISQ values. Sometimes, the two ISQ values were very close to each other, or even the same, if not, the mean of both values was used for statistical analysis. ISQ values were recorded for each patient, smartpeg was removed and ball attachment was rescrewed. If at any of mentioned visits, the ISQ fell to 45 or lower, the implant was considered a potential failure and placed under unloaded healing for 12 weeks prior to repeat stability testing. The mean of right and left implant measurements per patient was subjected to statistical analysis.

Statistical analysis was performed with SPSS (Statistical Package for Scientific Studies) for Windows and using student's t- test and paired t-test. The significance level was set at $\mathrm{P} \leq 0.05$.

\section{RESULTS}

The results of the present study are shown in tables (1-3). From the calculated data and its statistical analysis, the following results could be achieved:

- There were no statistically significant differences in marginal bone loss between mandibular overdentures retained by two platform switched implants and that retained by two platform matched implants, fig. (2). Also, there were no statistically significant differences in pocket depth or implant mobility between mandibular overdentures retained by two platform switched implants and that retained by two platform matched implants. 
TABLE (1): Marginal bone loss in GI and GII.

\begin{tabular}{|c|c|c|c|c|c|c|c|c|}
\hline & \multicolumn{4}{|c|}{ Right } & \multicolumn{3}{c|}{ Left } \\
\hline & \multicolumn{2}{|c|}{ Mesial } & \multicolumn{2}{c|}{ Distal } & \multicolumn{2}{c|}{ Mesial } & \multicolumn{2}{c|}{ Distal } \\
\hline Groups & G I & G II & G I & G II & G I & G II & G I & G II \\
\hline Mean difference & 0.700 & 0.500 & 0.500 & 0.829 & 0.543 & 0.700 & 0.371 & 0.686 \\
\hline Standard deviation & \pm 0.458 & \pm 0.271 & \pm 0.424 & \pm 0.377 & \pm 0.172 & \pm 0.252 & \pm 0.125 & \pm 0.367 \\
\hline P value & \multicolumn{3}{|c|}{0.429} & \multicolumn{3}{|c|}{0.061} & \multicolumn{3}{c|}{0.101} & \multicolumn{2}{c|}{0.056} \\
\hline
\end{tabular}

TABLE (2): Pocket depth in GI and GII.

\begin{tabular}{|c|c|c|c|c|}
\hline \multirow{2}{*}{ Time } & Groups & Mean & $\begin{array}{c}\text { Standard } \\
\text { deviation }\end{array}$ & P value \\
\hline \multirow{2}{*}{ Af loading } & GI & 1.5333 & 0.3466 & \multirow{2}{*}{$0.04 *$} \\
\cline { 2 - 4 } & GII & 0.85 & 0.202 & \\
\hline \multirow{2}{*}{ After 6 months } & GI & 1.2666 & 0.4224 & \multirow{2}{*}{0.359} \\
\cline { 2 - 4 } & GII & 1.53 & 0.443 & \multirow{2}{*}{0.108} \\
\hline \multirow{2}{*}{ After 12 months } & GI & 0.516 & 0.2312 & \multirow{2}{*}{ GII } \\
\cline { 2 - 4 } & 0.86 & 0.366 & \\
\hline
\end{tabular}

*: Significant.

TABLE (3): Implant mobility in GI and GII.

\begin{tabular}{|c|c|c|c|c|}
\hline Time & Groups & Mean & $\begin{array}{c}\text { Standard } \\
\text { deviation }\end{array}$ & \multirow{2}{*}{ P value } \\
\hline \multirow{2}{*}{ At loading } & GI & 68.20 & 6.979 & \multirow{2}{*}{0.506} \\
\cline { 2 - 4 } & GII & 71.40 & 7.537 & \\
\hline \multirow{2}{*}{$\begin{array}{c}\text { After 6 } \\
\text { months }\end{array}$} & GI & 71.60 & 5.320 & \multirow{2}{*}{0.577} \\
\cline { 2 - 4 } & GII & 73.00 & 4.301 & \multirow{2}{*}{0.404} \\
\hline \multirow{2}{*}{$\begin{array}{c}\text { After 12 } \\
\text { months }\end{array}$} & GI & 73.20 & 5.020 & \\
\cline { 2 - 4 } & GII & 74.75 & 2.630 & \multicolumn{2}{|c}{} \\
\hline
\end{tabular}

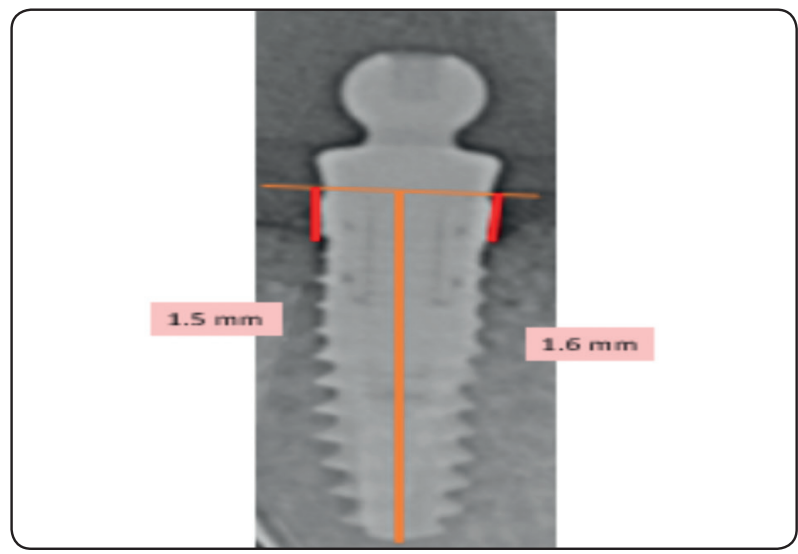

Fig. (2): Radiographic measurements for platform switched implant. Two oblique lines; marginal bone loss, the vertical line; radiographic implant length.

\section{DISCUSSION}

The current study sought to test the null hypothesis of no difference in success outcomes between the plaform switched and platform matched osseointegrated implants, against the alternative hypothesis of a difference. It was designed as a prospective comparative clinical trial with strict inclusion and exclusion criteria to remove variables that would lead to uncertinity in the validity of data.

The present study measured the marginal bone loss around platform switched and platform matched implants supported overdentures and soft tissue changes as regarding probing depth and implant stability at 12-month follow-up. 
The amount of marginal bone loss is considered an important criterion for the evaluation of implant therapy outcome and an evidence for the presence or absence of peri-implant tissue health. Therefore, efforts were made to preserve the peri-implant marginal bone stable throughout and following the prosthetic loading phase. ${ }^{(16)}$

Maximum survival and success was determined for the first year as all implants remained in function with healthy soft tissues and no signs of peri-implant infection, mobility or pain/discomfort. Radiographically, no implants presented continuous radiolucency or marginal bone loss at the proximal sides of the implant.

In the present study delayed implant loading protocol was followed. It was reported that, gradual bone loading is associated with superior bone healing and is more important in situations of compromised bone quality ${ }^{(17)}$. This is in disagreement with the result of study which found that immediate and delayed implant loading protocols seemed to produce similar results in mandibular overdenture treatments. ${ }^{(18)}$

The results of the marginal bone loss in the present study found that there were no statistically significant differences between mandibular overdentures retained by two platform switched and that retained by two platform matched implants. This indicates that crestal bone resorption is not influenced by platform switching. This may be due to bone resorption is most likely related to biological factors, such as biological width reestablishment, rather than to biomechanical factors, such as diameter of the abutment in relation to implant neck. ${ }^{(19)}$

These findings are in agreement with the results of study which found that platform switching may not be as crucial for maintenance of crestal bone level as presumed. It was concluded from a systematic review the role of platform switching remains debatable, bone loss seems to be influenced by multiple factors. ${ }^{(20,21)}$

The results of pocket depths in the present study found that there were no statistically significant differences between the two studied groups during the follow up periods except at loading. This indicates that probing depth is not influenced by platform switching. It was reported that probing depths around implants may be of little diagnostic value, unless accompanied by signs (eg, radiographic radiolucencies, purulent exudate, bleeding) and/ or symptoms (eg, discomfort, pain). According to that concept, increasing probing depths over time may indicate bone loss, but not necessarily indicate disease for an endosteal implant. These findings are in accordance with study reported insignificant differences in peri-implant probing depth when platform switched and plate matched implants were compared. ${ }^{(22,23)}$

There was an increase in implant stability during the follow up periods but they were non statistically significant. Also between both groups there was non statistically significant difference in ISQ values. This indicates that implant stability is not influenced by platform switching. It was concluded that primary stability was higher in the GI than GII, but this difference disappeared after 3 months of healing prior to loading. Differences for peri-implant health indices were negligible between platform switched and platform matched implant. Also, it was reported that the initial implant stability changed as a result of bone compression caused by mechanical bone relaxation, biological changes during the primary bone recovery stage and initiation of marginal bone resorption. ${ }^{(24,25)}$

\section{CONCLUSION}

Platform switching didn't influence marginal bone loss around implants or soft tissue supporting mandibular overdenture dentures. 


\section{REFRENCES}

1- Martínez J, Segura G, Faus J, Agustín R. Rehabilitation with implant-supported overdentures in total edentulous patients: a literature review. Journal of Clinical and Experimental Dentistry 2013; 5: 267-72.

2- Kuoppala R, Näpänkangas R, Raustia A. Quality of Life of Patients Treated With Implant-Supported Mandibular Overdentures Evaluated With the Oral Health Impact Profile (OHIP-14). Journal of Oral and Maxillofacial Research 2013 July 1; 4(2):e4.

3- Al-Nsour MM, Chan HL, Wang HL . Effect of the platform-switching technique on preservation of peri-implant marginal bone: a systematic review. Int J Oral Maxillofac Implants 2012; 27:138-45.

4- 4- Cumbo C, Marigo L, Somma F, La Torre G, Minciacchi I, D'addona A. Implant platform switching concept: a literature review. Eur Rev Med Pharmacol Sci. 2013 Feb $1 ; 17(3): 392-7$.

5- Molina A, Sanz-Sánchez I, Martín C, Blanco J, Sanz M.The effect of one-time abutment placement on interproximal bone levels and peri- implant soft tissues: a prospective randomized clinical trial. Clin Oral Implants Res 2017 Apr; 28(4):443-52.

6- Chaturvedi S, Verma A, Shrivastava R. Rejuvenating function through implant supported overdenture: a full mouth rehabilitation. Asian J Oral Health \& Allied Sciences 2012; 2: 96 - 100.

7- Alonso-González R, Aloy-Prósper A, Peñarrocha-Oltra D, Peñarrocha-Diago MA, Peñarrocha-Diago M. Marginal bone loss in relation to platform switching implant insertion depth: An update. J Clin Exp Dent 2012; 4(3):e173-9.

8- Kadkhoda Z, Amarlu Z, Eshraghi S, Samiei N. Antimicrobial effect of chlorhexidine on Aggregatibacter actino-mycetemcomitans biofilms associated with peri-implantitis. J Dent Res Dent Clin Dent Prospects 2016;10(3):176-80.

9- Sesma N, Garaicoa-Pazmino C, Zanardi PR, Chun EP, Laganá DC. Assessment of Marginal Bone Loss around Platform-Matched and Platform-Switched Implants - A Prospective Study. Braz Dent J 2016 Nov-Dec; 27(6):712-16.

10- Canullo L, Iannello G, Pe narocha M, Garcia B. Impact of implant diameter on bone level changes around platform switched implants: preliminary results of 18 months fol- low- up a prospective randomized match-paired controlled trial. Clinical Oral Implants Research 2012; 23:1142-46.

11- Canullo L, Iannello G, Netuschil L, Jepsen S. Platform switching and matrix metalloproteinase- 8 levels in periimplant sulcular fluid. Clin Oral Implants Res. 2012; 23:556-59.

12- De Angelis N, Nevins ML, Camelo MC, Ono Y, Campailla $\mathrm{M}$, Benedicenti S. Platform switching versus conventional technique: a randomized controlled clinical trial. Int J Periodontics Restorative Dent 2014; 34 Suppl 3:s75-79.

13- Aimetti M, Ferrarotti F, Mariani GM, Ghelardoni C, Romano F. Soft tissue and crestal bone changes around implants with platform-switched abutments placed nonsubmerged at subcrestal position: a 2-year clinical and radiographic evaluation. International Journal of Oral \& Maxillofacial Implants. 2015 Nov 1;30(6).

14- Malchiodi L, Cucchi A, Ghensi P, Nocini PF. Evaluation of the esthetic results of 64 nonfunctional immediately loaded postextraction implants in the maxilla: correlation between interproximal alveolar crest and soft tissues at 3 years of follow-up. Clin Implant Dent Relat Res 2013; 15(1):130-42.

15- Milillo L, Fiandaca C, Giannoulis F, Ottria L, Lucchese A, Silvestre F, Petruzzi M. Immediate vs non-immediate loading post-extractive implants: a comparative study of implant stability quotient (ISQ). Oral Implantol (Rome) 2016 Nov 13; 9(3):123-31.

16- Cassetta M. Immediate loading of implants inserted in edentulous arches using multiple mucosa-supported stereolithographic surgical templates: a 10-year prospective cohort study. Int J Oral Maxillofac Surg 2016 Apr; 45(4):526-34.

17- Saulacic N, Abboud M, Pohl Y, Wahl G. Implant-supported mandibular overdentures and cortical bone formation: clinical and radiographic results. Implant Dent. 2014; 23(1):85-91.

18- Hsu YT, Lin GH, Wang HL. Effects of Platform-Switching on Peri-implant Soft and Hard Tissue Outcomes: A Systematic Review and Meta-analysis. Int J Oral Maxillofac Implants 2017 Jan/Feb;32(1):e9-e24

19- Cassetta M, Di Mambro A, Giansanti M, Brandetti G, Calasso S. A 36-month follow-up prospective cohort study on peri-implant bone loss of Morse Taper connection implants with platform switching. J Oral Sci 2016; 58(1):49-57. 
20- Telleman G, Raghoebar GM, Vissink A, Meijer HJA. Impact of platform switching on inter-proximal bone levels around $8.5 \mathrm{~mm}$ implants in the posterior region; 5-year results from a randomized clinical trial. J Clin Periodontol 2017; 44: 326-36.

21- Zarandi A, Novin M. Marginal bone loss around platformswitched and non-platform switched implants after two years of placement: a clinical trial. J Dent Res Dent Clin Dent Prospects 2017; 11(1):26-9.

22- Al Amri MD, Al-Johany SS, Al Baker AM, Al Rifaiy MQ, Abduljabbar TS, Al-Kheraif AA. Soft tissue changes and crestal bone loss around platform-switched implants placed at crestal and subcrestal levels: 36-month results from a prospective split-mouth clinical trial. Clin Oral Implants Res 2016; 14:1-6.
23- Al Amri MD, Abduljabbar TS. Comparison of clinical and radiographic status of platform-switched implants placed in patients with and without type 2 diabetes mellitus: a 24-month follow-up longitudinal study. Clin Oral Implants Res 2017 Feb; 28(2):226-30.

24- Gultekin BA, Gultekin P, Leblebicioglu B, Basegmez C, Yalcin S. Clinical evaluation of marginal bone loss and stability in two types of submerged dental implants. International Journal of Oral \& Maxillofacial Implants 2013 Jun $1 ; 28(3): 815-23$

25- DI Girolamo M, Calcaterra R, DI Gianfilippo R, Arcuri C, Baggi L. Bone level changes around platform switching and platform matching implants: a systematic review with meta-analysis. Oral Implantol (Rome) 2016 Nov 13; $9(1): 1-10$. 